\title{
A study of distilled water and zamzam water as dielecric dense patch antenna at $5 \mathrm{GHz}$
}

\author{
N. H. Moktar ${ }^{1}$, W. I. Roseli ${ }^{2}$, M. T. Ali ${ }^{3}$, R. A. Awang ${ }^{4}$ \\ ${ }^{1,2}$ Electrical Engineering Department, Politeknik Sultan Idris Shah, Malaysia \\ ${ }^{3,4}$ Antenna Research Centre, Faculty of Electrical Engineering, Universiti Teknologi Mara, Malaysia
}

\begin{tabular}{|c|c|}
\hline Article Info & ABSTRACT \\
\hline Article history: & This paper was performed in order to study about distilled water and zamzam \\
\hline Received Oct 6, 2018 & This antenna is proposed and designed using FR-4 substrate that sandwiched \\
\hline Revised Jan 21, 2019 & together to perform DD structure. The proposed antennas employ simple \\
\hline Accepted Mar 2, 2019 & $\begin{array}{l}\text { rectangular structure that fed with inset feeder surround by electromagnetic } \\
\text { bandgap (EBG) structure.In order too enhance the gain, superstrate is applied }\end{array}$ \\
\hline Keywords: & $\begin{array}{l}\text { on top of the antenna. This antenna offers a wideband return loss of more } \\
\text { than }-10 \mathrm{~dB} \text { between } 4.41-5.52 \mathrm{Ghz} \text { (around } 22.2 \% \text { ) which can be applied }\end{array}$ \\
\hline Dielectric dense (DD) & $\begin{array}{l}\text { in } 5 \mathrm{Ghz} \text { applications. Details of DD water antenna of center frequency for } 5 \\
\text { Ghz is presented and discussed. }\end{array}$ \\
\hline
\end{tabular}

(EBG)

FR-4 substrate

Zamzam water

Corresponding Author:

N. H. Moktar,

Electrical Engineering Department,

Politeknik Sultan Idris Shah, Malaysia.

Email : sukma13@yahoo.com

\section{INTRODUCTION}

Microstrip antenna was focused because of several advantages compared to conventional antenna. The advantages includes low volume, light weight, low cost of fabrication, dual frequency and dual polarization antenna can be easily made, simple feed for linear and circular polarizations, feed lines and matching networks can be fabricated with antenna structure [1-5]. However, microstrip antenna also facing some limitations compare to conventional antennas. The limitations include narrow bandwidth, lower gain, high metallic loss and lower power handling [1].

In 1980s, Stuart Long was developed a dielectric resonator antenna (DRA) in while microstrip antenna progressively explored [6]. There are many researchers interested in DRA because of its low loss, believed to be useful and good radiator and unique features differ from metallic patches [7-14]. Dielectric resonator antenna (DRA) is antenna which mounted directly above ground plane [6]. Referring to this DR structure will excited $\mathrm{HEM}_{11}$ mode [15]. Other than exciting at the high dielectric material in $\mathrm{HEM}_{11}$ DRmode, researched has been discovered that a $\mathrm{TM}_{11}$ cavity mode also can be excited in the region between circular dielectric resonator and metallic ground plane. This concept of antenna is designated as dense dielectric (DD) patch antenna. Dense dielectric (DD) patch antenna notion is considered as family of patch antenna rather than DRA. DD patch antenna is expected has higher efficiency compared to metallic conventional antenna, especially at higher frequencies where the radiation efficiency of microstrip antenna becomes low [16, 18-19].

Then, microstrip antenna also facing some limitations compare to conventional antennas. The limitation includes narrow bandwidth and high metallic loss [1]. Therefore, recently researcher widely proposed another material to replace metallic microstrip antenna in order to overcome the high metallic loss [17, 20-22]. Material that proposed must be easy to get, low cost, and can give good performance to the 
antenna design. Thus, water material is suitable to meet all the requirement to replace metallic antenna due to water has similar performance as well as the metallic microstrip antenna at the lower microwave frequencies [20].

Besides that, water is an alluring material to replace metallic due to it can give good performance and high permittivity as well as metallic microstrip patch antenna at lower microwave frequencies [20-21]. Most of the early studies of water antenna using fresh water had been recorded in [20, 22]. There are some advantages of using water such as easy available and green material. At lower frequency, pure water has high dielectric constant which can serve as a good choice for DDPA [20]. Figure 1 show the dielectric permittivity and loss tangent of pure water.

Other than that, zamzam water is holy water for Muslim which is very interesting material to discover.Surprisingly, zamzam water is very suit material material which can replaced metallic antenna. Researchers had investigated that zamzam water has higher electrical conductivity $(1390 \mu \mathrm{S} / \mathrm{cm})$ compared to bottled water $(740 \mu \mathrm{S} / \mathrm{cm})$. Figure 2 show the comparison of water samples properties from Zamzam with two samples of bottled drinking and distilled waters analysed by [23].

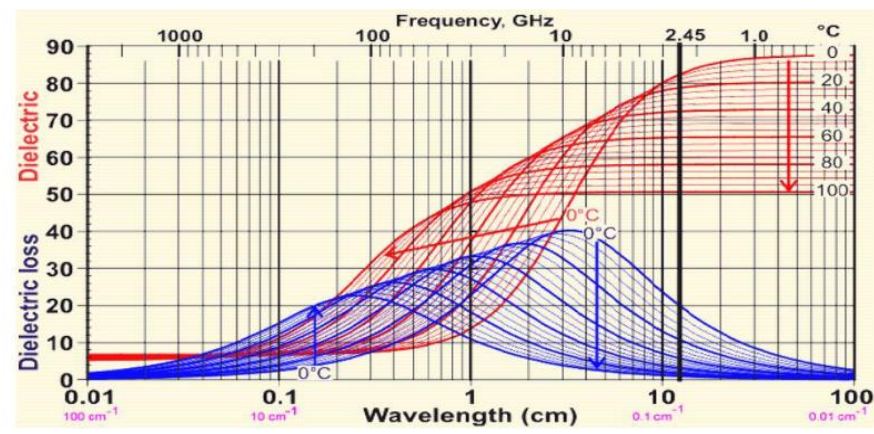

Figure 1. Dielectric permittivity and tangent loss of pure water

\begin{tabular}{|c|c|c|c|}
\hline Parameter & Zamzam water & $\begin{array}{l}\text { Bottled drinking } \\
\text { water }\end{array}$ & Distilled water \\
\hline Appearance & Clear & Clear & Clear \\
\hline Odor & Acceptable & Acceptable & Acceptable \\
\hline Turbidity & Nil & Nil & Nil \\
\hline Suspended solids & Nil & Nil & Nil \\
\hline Total dissolved solids & 1000 & 452 & - \\
\hline $\mathrm{pH}$ & 7.73 & 7.21 & 6.85 \\
\hline Conductivity $(\mu \mathrm{S} / \mathrm{cm})$ & 1390 & 740 & 0.5 \\
\hline Residual chlorine & Nil & 0.45 & Nil \\
\hline Total hardness & 300 & 228 & 0.2 \\
\hline Calcium & 220 & 136 & 0.1 \\
\hline Magnesium & 80 & 92 & 0.1 \\
\hline Alkalinity $\left(\mathrm{CO}_{3}\right)^{-2}$ & Nil & Nil & Nil \\
\hline Alkalinity $\left(\mathrm{HCO}_{3}\right)^{-2}$ & 110 & 108 & 0.2 \\
\hline Chlorides & 260 & 100 & 0.1 \\
\hline Floride & 0.59 & 0.32 & 0.1 \\
\hline Sulfates & 180 & - & Nil \\
\hline Nitrates & 31.6 & - & 10 \\
\hline Phosphate & 0.15 & 0.13 & - \\
\hline Ammonia & 0.11 & 0.06 & Nil \\
\hline Iron & 0.06 & 0.05 & Nil \\
\hline Copper & 0.04 & - & - \\
\hline Silica & 37.6 & 11.3 & - \\
\hline
\end{tabular}

Results in mg/L, NTU (nephlometric turbidity units).

Figure 2. Comparison between Zamzam water bottled drinking water and distilled water parameters study

In this paper, a material of distilled water and zam zam water patch are study and compare when operate at $5 \mathrm{GHz}$ communication applications. The calculated results show that proposed antenna can be achieved reflection coefficient $\mathrm{S}_{11}$ less than $-10 \mathrm{~dB}$ over the 4.41-5.52Ghz (around $22.2 \%$ bandwidth). Futhermore, in section 2, we describe about the structure of antenna design including of patch design and optimization by using EBG and superstrate. The proposed antenna results and analysis are presented and discussed in section 3. Lastly, the conclusion of this work is state in section 4. 


\section{PROPOSED DD PATCH ANTENNA ELEMENT}

The proposed antenna employs simple rectangular structure that fed with inset feeder surround by electromagnetic bandgap (EBG) structure. EBG always be referred as high impedance surface that increase antenna efficiency by suppressing the unwanted surface wave current. By inserting EBG, helps to improve antenna performance such as backward radiation [24-25]. The antenna is printed on FR-4 dielectric substrate of thickness $\mathrm{h}=1.6 \mathrm{~mm}$, tangent loss of 0.019 and relative permittivity of $\varepsilon_{\mathrm{r}}$ of 4.7 . The dimensions of both substrate layers are $26 \mathrm{~mm} \times 34 \mathrm{~mm}$. The four patches of antenna are using the same size and can be calculated using formula below [6]:

Width of the patch, W:

$$
W=\frac{\left.c\left[\left(\varepsilon_{\mathrm{r}}+1\right) / 2\right)\right]^{-\frac{1}{2}}}{2 \mathrm{fo}_{\mathrm{o}}}
$$

The length of the patch:

$$
\mathrm{L}=\frac{\mathrm{c}}{\left(2 \mathrm{f}_{\circ} \sqrt{\varepsilon_{\theta}}\right)}-2 \Delta \mathrm{L}
$$

where $\varepsilon$ and $\Delta \mathrm{L}$ are

$$
\varepsilon_{\mathrm{e}}=\frac{\varepsilon_{\mathrm{r}}+1}{2}+\frac{\varepsilon_{\mathrm{r}}-1}{2}\left[1+\frac{12 \mathrm{~h}}{w}\right]^{-\frac{3}{2}}
$$

and,

$$
\Delta \mathrm{L}=0.412 h\left[\frac{\left.\varepsilon_{\mathrm{r}}+0.300\right)}{\varepsilon_{\mathrm{r}}-0.258}\right]\left[\frac{\left.\frac{W}{h}+0.264\right)}{\frac{W}{\mathrm{~h}}+0.800}\right]
$$

In this design, superstrate is place on top of the antenna. Patches are placed on top of first substrate, while the bottom of second substrate printed the feedline and Electromagnetic Bandgap (EBG). The ground

\begin{tabular}{|c|c|}
\hline Antenna Part & Characteristics \\
\hline Shape & Rectangular antenna + monopole antenna for inset feed \\
\hline \multirow[t]{7}{*}{ Superstrate ,Substrate $1 \& 2$} & Material = FR -4 \\
\hline & Dielectric Constant, $\varepsilon_{r}=4.7$ \\
\hline & Tangent Loss, $\tan \sigma=0.019$ \\
\hline & Thickness, $\mathrm{h}=1.6 \mathrm{~mm}$ \\
\hline & Size $=W_{s} \times L_{s}$ \\
\hline & $=47.48 \times 43 \mathrm{~mm}$ (calculated) \\
\hline & $=40 \mathrm{~mm} \times 26 \mathrm{~mm}$ (optimized) \\
\hline Frequency of operation & $5 \mathrm{GHz}$ \\
\hline \multirow[t]{2}{*}{ Ground Plate Copper Plate } & Material $=$ Copper \\
\hline & Thickness, $\mathrm{h}=0.035 \mathrm{~mm}$ \\
\hline \multirow{5}{*}{ Distilled water Dielectric Dense Patch } & Material $=$ acrylic + distilled water \\
\hline & Thickness, $\mathrm{h}=1.3 \mathrm{~mm}$ \\
\hline & Size $=W_{s} \times L_{s}$ \\
\hline & $=18.26 \mathrm{~mm} \times 13.76 \mathrm{~mm}$ (calculated) \\
\hline & $=36 \mathrm{~mm} \times 13.7 \mathrm{~mm}($ optimized $)$ \\
\hline \multirow{5}{*}{$\begin{array}{l}\text { Zamzam water Dielectric Dense Patch } \\
\text { (optimize value) }\end{array}$} & Material $=$ acrylic + zamzam water \\
\hline & Thickness, $\mathrm{h}=1.3 \mathrm{~mm}$ \\
\hline & Size $=W_{s} \times L_{s}$ \\
\hline & $=18.26 \mathrm{~mm} \times 13.76 \mathrm{~mm}$ (calculated) \\
\hline & $=26 \mathrm{~mm} \times 13.7 \mathrm{~mm}($ optimized $)$ \\
\hline Inset type & Inset feed \\
\hline Electromagnetic Bandgap (EBG) & Size $=\mathrm{W}_{\mathrm{EBG}} \times \mathrm{L}_{\mathrm{EBG}}=1 \mathrm{~mm} \times 1 \mathrm{~mm}$ \\
\hline
\end{tabular}
is sandwiched between both substrates. Both substrates are use is FR-4 with the same relative permittivity tangent loss. The optimization of feedline width is done due to maintain the impedance characteristic of $50 \Omega$.

Table 1. Structure of Dielectric Dense (DD) Patch Antenna 
The antennas first designed by using distilled water as a patch of antenna which acts as reference design. Then, the distilled water is switched by Zamzam water as patch of antenna. The size been optimize to get good performance of antenna. The antenna structure is as shown in Figure 3. For further gain improvement, a dielectric layer of superstate is applied above the antenna. Meanwhile, for return loss and bandwidth enhancement, EBG is designed at the bottom of antenna. The topology of EBG is as shown in Figure 4. The conductivity parameter of both water is experimentally test by using HI-991300 $\mathrm{pH} / \mathrm{EC} / \mathrm{TDS} /{ }^{\circ} \mathrm{C}$ handheld meter and the complex dielectric permittivity of water-based liquids for both is measured by using Keysight Dielectric Probe 85070E (performance probe). Result for both experimental parameters written in Table 2.
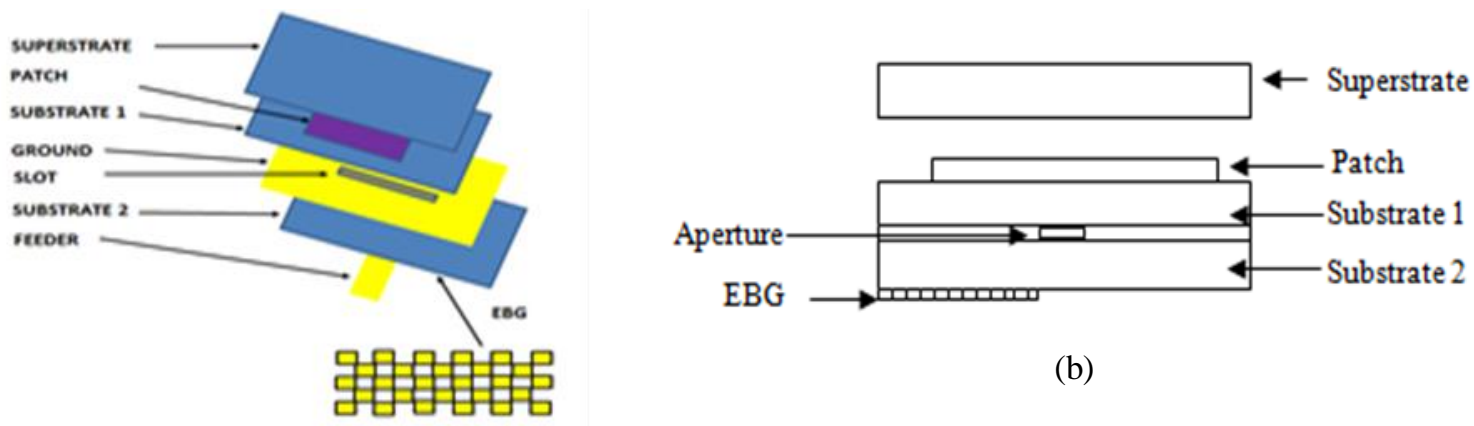

(b)

(a)

Figure 3. (a) General and (b) side view of microstrip distilled water antenna

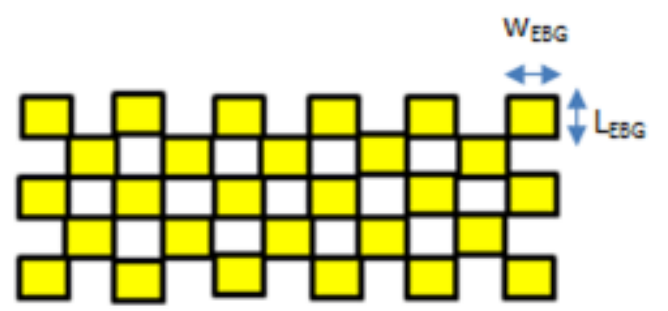

Figure 4. EBG topology

Table 2. Parameters of Distilled water and Zamzam Water

\begin{tabular}{ccc}
\hline Types of water & Dielectric permittiviy, $\varepsilon_{\mathrm{r}}$ & Tangent loss, $\tan \sigma$ \\
\hline Distilled water & 75.81 & 0.24 \\
Zamzam water & 77.61 & 0.24 \\
\hline
\end{tabular}

\section{RESULTS AND ANALYSIS}

\subsection{Simulation}

The antenna is designed by using distilled water patch as initial designed. This designed is simulated by using CST Design Environment and the result of return loss, $S_{11}$ is as shown in Figure 5. The result of $\mathrm{S}_{11}=-17.18 \mathrm{~dB}$ at resonance frequency of $5 \mathrm{GHz}$. The patch distilled water antenna then is changed to Zamzam water and the value of return loss $S_{11}=-45.6 \mathrm{~dB}$ for frequency resonant of $5 \mathrm{GHz}$. The operating frequency for Zamzam water patch antenna below $-10 \mathrm{~dB}$ is between 4.41-5.52 GHz (around 22.2\%) as shown in Table 3. The proposed antenna is considered as good candicates for $5 \mathrm{GHz}$ communication applications.

Table 3. Result performance of distilled and Zamzam water dielectric dense patch antenna

\begin{tabular}{ccll}
\hline Type of Water & $5 \mathrm{GHz}$ & Range Frequency Resonance & \multicolumn{1}{c}{ Bandwidth } \\
\hline Distilled water & $-17.18 \mathrm{~dB}$ & a) $4.97 \mathrm{GHz}-5.04 \mathrm{Ghz}$ & a) $0.07 \mathrm{GHz}(1.4 \%)$ \\
& & b) $5.83 \mathrm{GHz}$ to $5.89 \mathrm{Ghz}$ & b) $0.06 \mathrm{GHz}(1.2 \%)$ \\
Zamzam water & $-45.6 \mathrm{~dB}$ & a) $4.4-5.51 \mathrm{Ghz}$ & a) $1.11 \mathrm{GHz}(22.2 \%)$ \\
& & b) 7.11 to $9.69 \mathrm{Ghz}$ & b) $2.58 \mathrm{GHz}(51.6 \%)$ \\
\hline
\end{tabular}




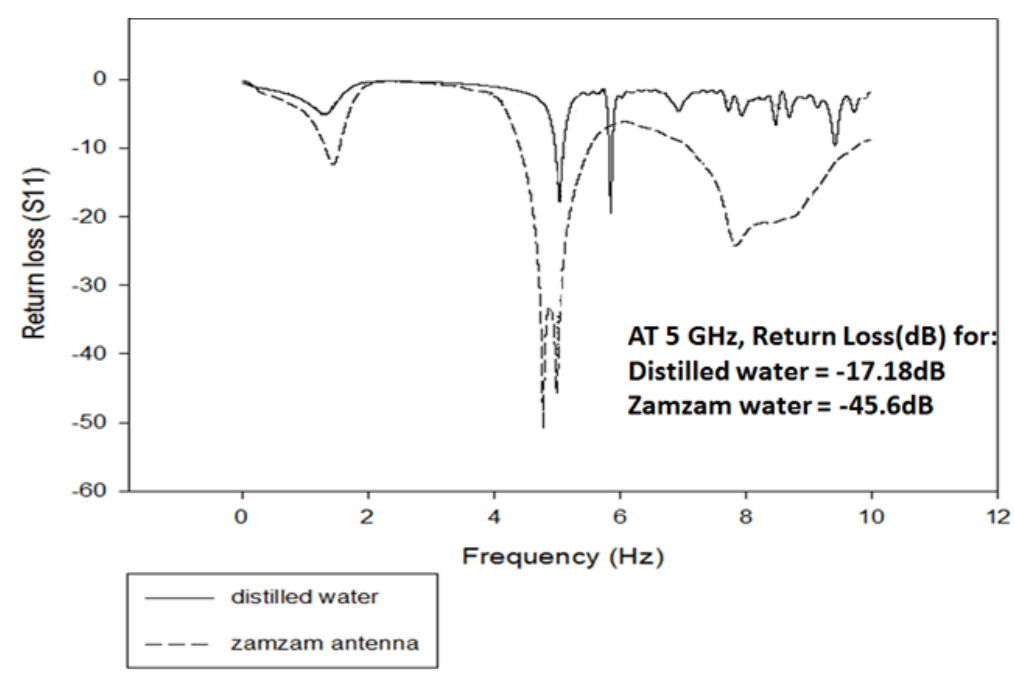

Figure 5. Simulation of Distilled water and Zamzam water patch antenna

Then, the structure is integrated with EBG and surprisingly, EBG can help in order to increase the return loss value. After using EBG the value of $S_{11}$ become $=-45.6 \mathrm{GHz}$. Without EBG, the $S_{11}=-20.169 \mathrm{~dB}$. From the result, it can be conclude by using EBG performance of antenna can be better than without using EBG. The simulation result is shown in Figure 6.

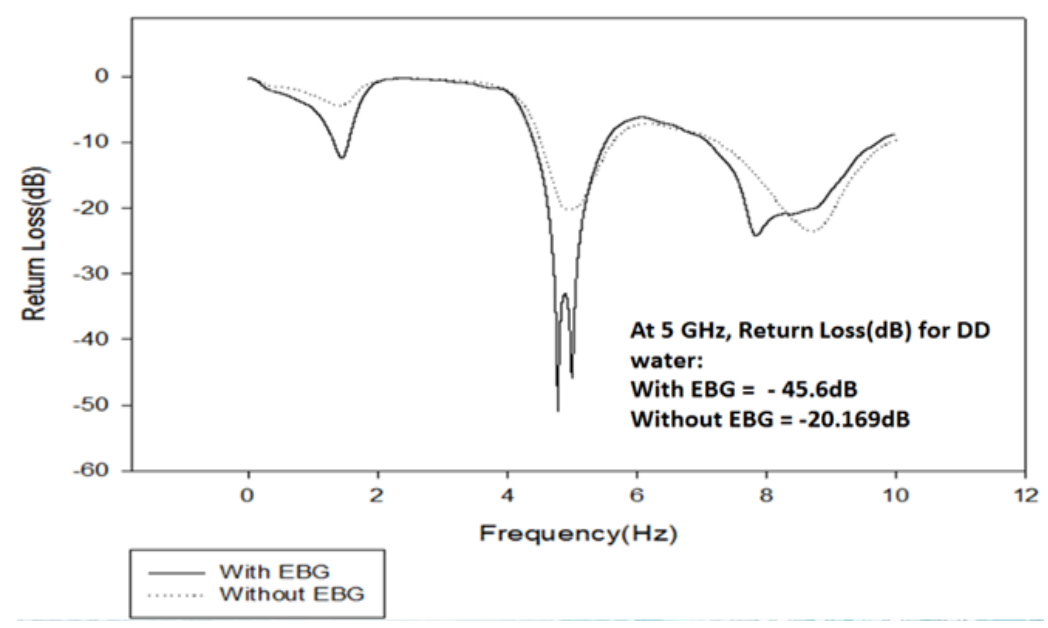

Figure 6. Simulation of with and without EBG for DD water antenna

The antenna then simulated by adding superstrate on the top layer of antenna by the distance of $\mathrm{H}_{\mathrm{s}}$. The Zamzam antenna is simulated in order to investigate the effect of superstrate to that antenna. The simulation with and without superstrate is as shown in Figure 7. Figure 8(a) and (b) show the gain after simulation of Zamzam water which is $1.397 \mathrm{~dB}$. Figure $8(\mathrm{c})$ show the gain in $3 \mathrm{D}$ without using superstrate that is -3.008 . Therefore, that can be conclude that by applying superstrate the gain is improving. Figure 8(d) show the gain in phi $=90^{\circ}$ for Zamzam water patch antenna that is $-5.9 \mathrm{~dB}$. By applying EBG can reduce the backlobe reduction by $0.3 \mathrm{dBi}$. 


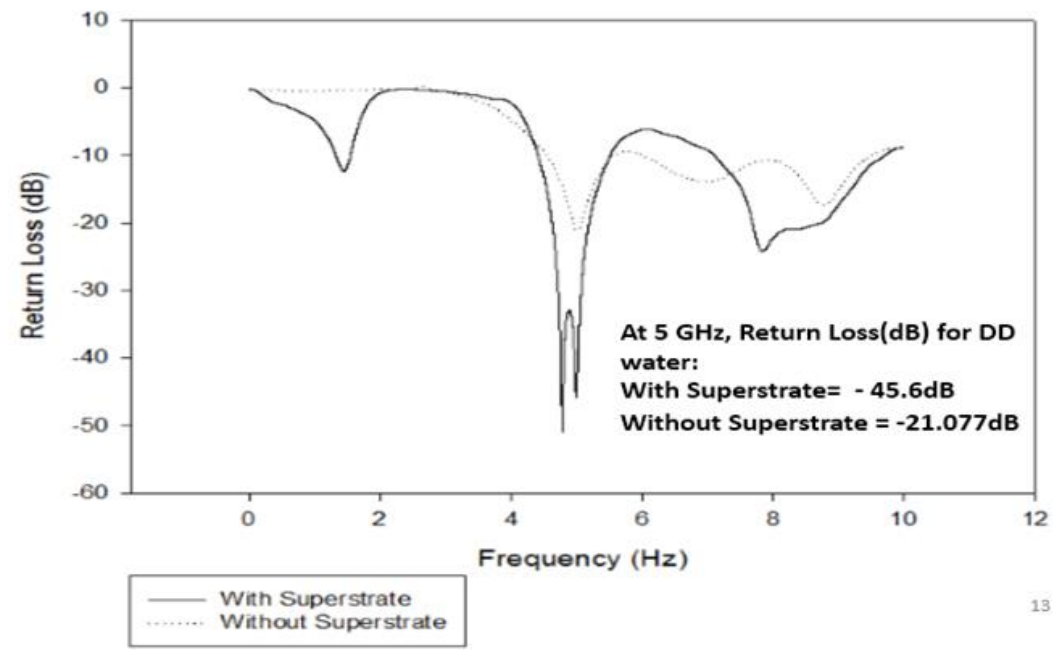

Figure 7. Simulation of with and without superstrate for DD water antenna

Farfield Gain Abs (Phi=90)

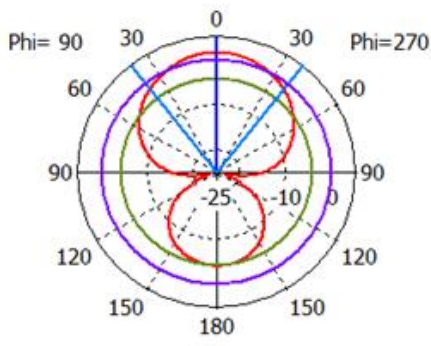

Theta / Degree vs. dB

(a) phi $90^{\circ}$ ( backlobe $\left.-5.6 \mathrm{~dB}\right)$

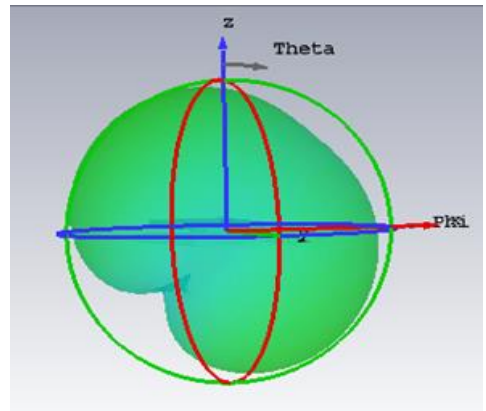

(c) $3 \mathrm{D}$

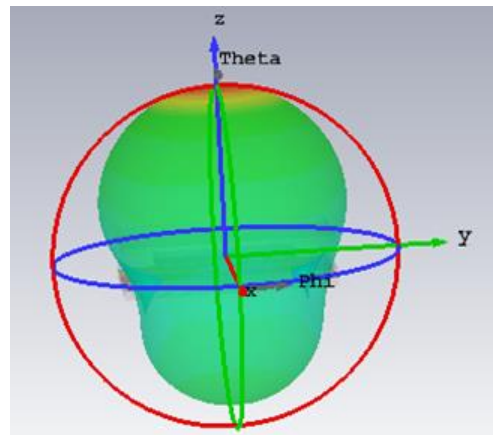

(b) $3 \mathrm{D}$

Farfield Gain Abs (Phi=90)

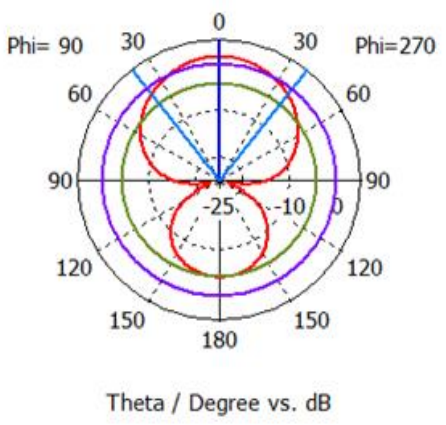

(d) phi $90^{\circ}$ (backlobe at $-5.9 \mathrm{~dB}$ )

Figure 8. (a) Gain for Zamzam water at phi $90^{\circ}$, (b) Gain for Zamzam water in 3D, (c) Gain for Zamzam without superstrate in 3D, (d) Gain for Zamzam water without EBG at phi $90^{\circ}$

\subsection{Measurement}

Both of structure distilled water and Zamzam water patch antenna are fabricated using FR-4 substrate and measurement process has been carried out. The distilled water patch antenna perform return loss, $\mathrm{S}_{11}=-16.96 \mathrm{~dB}$ at $5.01 \mathrm{GHz}$ while Zamzam water patch antenna give return loss of $-16.52 \mathrm{~dB}$ at resonance frequency $5.03 \mathrm{GHz}$ as shown in Figure 9. This discrepancies is due to problem arises in fabrication process. 

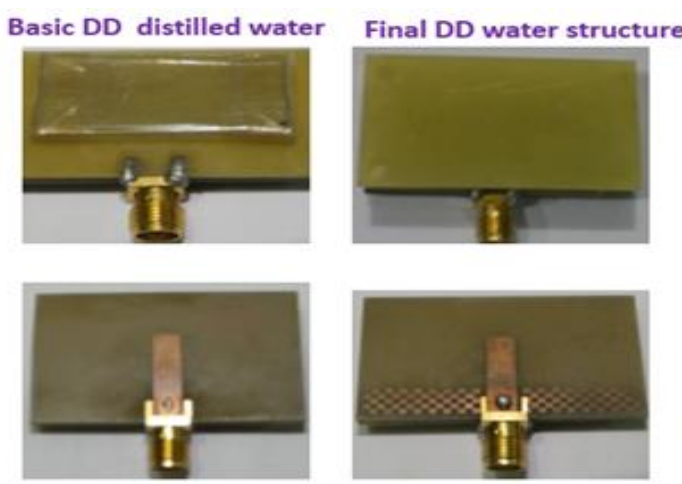

Figure 9. Antenna prototype

\section{CONCLUSION}

In this paper the DD antenna for wireless communication application was designed. With an overall adjustment, the antenna using zamzam water shows good agreement that can be operated between 4.41-5.52 $\mathrm{GHz}$ and 7.1153 to $9.7034 \mathrm{GHz}$ frequency band. The final result shows good good radiation pattern and gain for the DD structure. Due to its light and small size, the antenna can be easily integrated in $5 \mathrm{GHz}$ communication applications.

\section{ACKNOWLEDGEMENTS}

The authors would like to give appreciation towards Antenna Research Centre (ARC), Faculty of Electrical Engineering, Universiti Teknologi MARA (UiTM), for providing facilities to conduct the present research.

\section{REFERENCES}

[1] R. Garg, et al., "Microstrip Antenna Design Handbook,” London, Artech House Boston, 2001.

[2] A. Kuruvilja, "The Design and Analysis of Microstrip Patch Antenna for Smart Connectors," Utah State University, 2003.

[3] C. A. Balanis, "Antenna Theory-Analysis and Design," $3^{\text {rd }}$ ed., John Willey \& Son, Inc, USA, 2005.

[4] K. L. Wong, "Compact and Broadband Microstrip Antennas," Jon Wiley \& Sons, Inc., 2002.

[5] J. R. James, et al., "Microstrip Antenna Theory and Design," Peter Perigrinus, London, 1981.

[6] S. A. Long, et al., "The resonant cylindrical dielectric cavity antenna," IEEE Transactions on Antennas and Propagation, vol. 31, pp. 406-412, May 1983.

[7] A. A. Kishk, et al., "Accurate prediction of radiation patterns of dielectric resonator antennas," Electron. Lett, vol. 23, pp. 1374.

[8] A. A. Kishk, et al., "Broadband stacked dielectric resonator antennas," Electron. Lett, vol. 25, pp. 1232-1233, 1989.

[9] K. W. Leung, et al., "Input impedance of aperture coupled hemispherical dielectric resonator antenna," Electron. Lett., vol. 27, pp. 2259-2260, 1991.

[10] R. K. Mongia, et al., "Measurements of radiation efficiency of dielectric resonator antennas," IEEE Microw. Guided Wave Lett, vol. 4, pp. 80-82, Mar 1994.

[11] A. Petosa, et al., "Magnetically tunable ferrite resonator antenna," Electron. Lett., vol. 30, pp. 1021-1022, 1994.

[12] K. W. Leung, et al., "Characteristics of a low-profile circular disk DR antenna with very high permittivity," Electron. Lett, vol. 31, pp. 417-418, 1995.

[13] K. W. Leung, et al., "Lowprofile circular disk DR antenna of very high permittivity excited by a microstrip line," Electron. Lett., vol. 33, pp. 1004-1005, 1997.

[14] M. T. K. Tam and R. D. Murch, "Half volume dielectric resonator antenna designs," IEE Electron. Lett., vol. 33, pp. 1914-1916, 1997.

[15] A. A. Kishk, et al., "A numerical study of a dielectric disk antenna above grounded dielectric substrate," IEEE Trans.Antennas Propag., vol. 41, pp. 813-821, Jun 1993.

[16] H. W. Lai, et al., "Dense Dielectric Patch Antenna -A new kind of Low Profile Antenna Element for Wireless Communications," IEEE Trans. Antennas Propag., vol. AP-61, pp. 4239-4245, Aug 2013.

[17] S. G. o'Keefe and S. P. Kingsley, "Tunability of liquid dielectric resonator antennas," IEEE Antennas Wireless Propag. Lett., vol. 6, pp. 533-536, 2007.

[18] O. M. Haraz, et al., "New dense dielectric patch array antenna for future 5G short-range communications," Proceedings - ANTEM 2014: 2014 16th International Symposium on Antenna Technology and Applied Electromagnetics, 2014. 
[19] Q. Lai, et al., "Comparison of the radiation efficiency for the dielectric resonator antenna and the microstrip antenna at Ka band," IEEE Trans. Antenna Propag., vol. 56, pp. 3589-3592, Nov 2008.

[20] A. Technologies, et al., "Study and Design of a $2 \times 2$ Water Dielectric Patch Antenna Array for Wi - Fi Application," vol. 62, pp. 5968-5973.

[21] Y. Li and K. M. Luk, "A transparent water dielectric patch antenna," Proceedings of the 2015 IEEE 4th AsiaPacific Conference on Antennas and Propagation, APCAP 2015, vol. 2, pp. 319-320, 2016.

[22] J. Sun and K. M. Luk, "Design of $4 \times 4$ aperture-coupled water patch antenna array," TENCON 2015 - 2015 IEEE Region 10 Conference, pp. 1-3, 2015.

[23] S. H. Fatani and A. T. Babakr, "Effect Of Water Intake Pattern on Serum Mineral and Electrolyte Levels in Makkah People," vol. 1, pp. 442-456, 2014.

[24] A. K. Gupta and P. K. Singhal, "Microstrip antenna Parameters Improvement Using EBG Structure," in International Journal of research in engineering \& Technology (IJERT), vol. 11, pp. 35-40, Aug 2013.

[25] P. Vats and D. Dabas, "Design analysis of Patch antenna without EBG and with cross-shape EBG and Analyse the Effect of Different Feed Position," in International Journal of Engineering Trends and Technology (IJETT), vol. 7, pp. 3086-3089, 2013.

\section{BIOGRAPHIES OF AUTHORS}
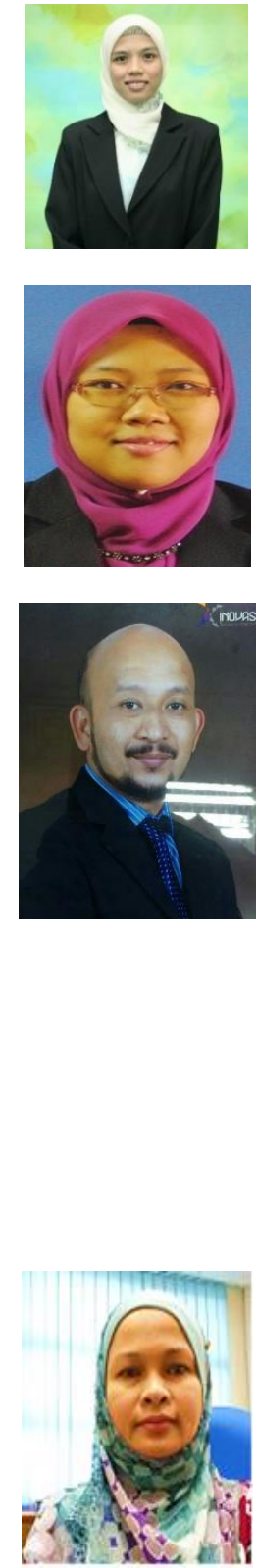

Nur Hidayah Moktar received the B. Eng. Degree (Hons.) from Universiti Tun Hussien Onn Malaysia (UTHM), Johor, Malaysia in 2008 and M. Sc. degree in Telecommunication and Information Engineering from Universiti Teknologi Mara (UiTM), Shah Alam, Malaysia in 2013. She is currently a Lecturer at Politeknik Sultan Idris Shah (PSIS), Sabak Bernam, Selangor, Malaysia and post-graduate student in UiTM, Shah Alam. Her current research interests include antenna and materials of antennas in communication.

Wan Izma Izniza Mohamed Roseli received the B. Eng. Degree (Hons.) from Universiti Tun Hussien Onn Malaysia (UTHM), Johor, Malaysia in 2004 and M. Sc. degree in Telecommunication and Information Engineering from Universiti Teknologi Mara (UiTM), Shah Alam, Malaysia in 2014. She is currently a Lecturer at Politeknik Sultan Idris Shah (PSIS), Sabak Bernam, Selangor, Malaysia and post-graduate student in UiTM, Shah Alam. Her current research interests include reconfigurable antennas in wireless communications.

Mohd Tarmizi Ali received the B.Eng. degree in electrical engineering from the Universiti Teknologi Mara (UiTM), Shah Alam, Malaysia, in 1996, the M.Sc. degree in electrical engineering from the University of Leeds, Leeds, U.K., in 2002, and the Ph.D. degree in electrical engineering from the Universiti Teknologi Malaysia (UTM), Johor, Malaysia, in 2010. On October 2018, he has been a Professor with the Faculty of Electrical Engineering (FKE), UiTM, and since 2011 he has been appointed as the Group Leader of the Antenna Research Center (ARC), FKE UiTM. He is a senior member for the IEEE and the member for the Antenna Propagation/Microwave Theory and Technology/Electromagnetic Compatibility (AP/MTT/ECM) Joint Chapter. He has authored more than 100 journal papers and conferences proceedings on various topics related to antennas, microwaves, and electromagnetic radiation analysis. He has also filed five patent applications on communication antennas. His research interests include the areas of communication antenna design, radio astronomy antennas, satellite antennas, and electromagnetic radiation analysis. Professor Ts. Dr Tarmizi was the Chair and Technical Program Chair of the IEEE Symposium on Wireless Technology and Applications, between 2011 and 2012. He has been a very promising as a Researcher, with the achievement of several International Gold Medal Awards, a Best Invention in Telecommunication Award, and a Special Chancellor Award from UTM for his contribution to research and innovation and was the recipient of Postgraduate Best Student Award 2011 from UTM.

Robiatun A. Awang received the B.Eng. degree (Hons.) and M.Eng. degree in computer \& communication engineering from Universiti Kebangsaan Malaysia (UKM), Malaysia in 2001 and 2005, respectively, and the Ph.D. degree from RMIT University, Melbourne, VIC, Australia, in 2016. She is currently a senior lecturer with Faculty of Electrical Engineering, Universiti Teknologi MARA (UiTM), Shah Alam, Malaysia. Her current research interests include antennas, microwave sensors and flexible and tunable electromagnetic devices. 